\title{
Sales information systems: Are they being used for more than simple mail shots?
}

Received (in revised form): 14th November, 2001



\section{Bill Donaldson}

is Senior Lecturer in Marketing at the University of Strathclyde, Graduate School of Business in Glasgow. He is the author of 'Sales management: Theory and practice', and his latest book, 'Strategic market relationships', is published by Wiley. His research interests areas are in sales and relationship marketing.

\section{George Wright}

is Professor of Management at the University of Strathclyde, Graduate School of Business in Glasgow. He is author and editor of a wide range of publications on management issues and is currently the editor of the Journal of Behavioral Decision Making. His latest book, 'Strategic decision making', is published by Wiley.

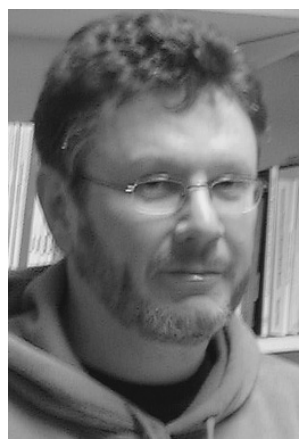

Abstract The enthusiastic acceptance of database marketing by financial services firms has caused a fundamental re-examination of the exchange process between supplier and end user. Surprisingly, empirical research in this industry has, in many cases, overlooked the role of personal selling or intermediary. This paper addresses this agenda by reporting on a quantitative survey of a key aspect of IT in marketing, the use of sales force automation (SFA) and sales information systems (SIS) to target and interface with key customers. The lack of empirical research material on this issue justifies a prime direction in this research, namely the characteristics and aspirations of firms in adoption of these systems. Sales managers can use SIS for account initiation, management and development of the sales role involving high level and frequent customer contact. The research results show, however, that the sophisticated potential of SIS is not being achieved in practice.

\section{INTRODUCTION}

The purpose of this paper is to present and discuss empirical findings from the financial services industry on the level of sophistication of sales automation systems and the satisfaction of managers with the outcomes from the use of such systems. The enthusiastic acceptance of database marketing by financial services firms has caused a fundamental re-examination of the exchange process between supplier and end user but at the expense of the intermediary/firm interface.

The key account manager of yesterday is today's strategic account manager and tomorrow's global account manager. The service salesperson of yesterday is today's category manager and tomorrow's customer liaison manager and the technical salesperson of yesterday is today's product specialist and tomorrow's business development manager. Of course, in the world of Internet and IT, the conventional salesperson who does cold calling or service selling will find the role changed by more senior salespeople, by telesales back up and by technology itself. Even more under threat are the traditional market researcher and brand product manager as 
they become replaced by real-time information, corporate rather than individual brands or own label supplies and by outsourcing of customer-based audits, benchmarking and consulting services.

Surprisingly, this trend is not uniform among firms, even those operating in the same sector of the same industry. For example, the Royal Bank of Scotland in an apparently innovative move have announced significant investment in staff to interface with customers, a move away from the call centre trend of some of their competitors. ${ }^{1}$ There are also examples of the reverse situation. Prudential's dramatic cuts in personal selling, reducing their sales force from 2,500 to under 100 key account managers is one, not untypical, example. It is not always clear, however, what is meant by a sales force. The traditional image would be of a person, until recently almost certainly male, attempting to sell a range of products and services being paid basic salary with commission and/or bonuses based on results achieved. It all seemed so simple then compared with today. Now, radical changes in the way prospects and existing customers interact is quite different. Salespeople, if that is what they are, mobilise company resources around customer solutions. This incorporates sophisticated software, telephone and on-line applications and more complex networks of advisers, retailers and service support people and organisations. For example, in stockbroking personal contact is important but the change to a 'bear' market has helped drive the growth in execution-only broking and the value of personal, face-to-face advice downward.

Selling to customers has been replaced by cooperation with customers. The traditional goals and objectives for the salesperson to achieve or exceed target, selling $\mathrm{X}$ products in $\mathrm{Y}$ period and to maximise earnings are no longer enough. The salesperson must build repeat business with the firm's existing and potential customer base. In response therefore sales information systems (SIS) and sales force automation systems (SFA) are increasingly used as part of the customer relationship management (CRM) solution. ${ }^{2}$ SIS is a collaboration of data technologies that facilitate the collection and processing of information to assist the sales process. SFA is concerned with the integration of the front and back office to facilitate an information-empowered sales force that can improve sales force activity and enhance the relationship. ${ }^{3}$ As yet, there is very little research into what this entails for salespeople in terms of the time spent with customers and targeting the best prospects.

Clearly, the interactive communication of the salesperson with customers is high in the sales management agenda of customer orientated firms, nevertheless 'closing the sale' has been the main driving force behind the sales management efforts of the firm in the past. Today, relationship marketing and CRM have shifted attention from 'closing' the singular sale to creating the necessary conditions for a long-term relationship between the firm and its customers that breeds successful sales encounters in the long run. This shift renders obsolete many of the currently available sales management practices and the sales philosophy and culture that have driven the development of the sales management field for decades. It also questions sales performance measures based on individual and organisational goals and on sales management practices that still reflect recruitment, training and rewards based on sales volumes rather than relationship performance.

The lack of empirical research material on the above issues justifies a prime 
direction in future research, namely the in-depth examination of how firms target their most profitable prospects and how salespeople decide to spend time on initiating, building and maintaining their customer contacts. There are many proprietary systems for sales automation on the market. Most claim to offer huge productivity improvements and put companies in touch with their customers. Yet results are poor. Why? Specifically, questions such as the following need to be answered:

- what aspects of sales automation systems do firms use to manage their sales force and customer contacts

- how well do these systems work

- what are the benefits and problems with such systems

- how do firms compare in their level of sophistication?

\section{SALES AUTOMATION SYSTEMS}

Traditionally, the role of salespeople has been perceived as crucial for the implementation (delivery) stage of the firm's operational marketing plans. The complexity of the relationship process, however, necessitates a more advanced role for salespeople. Clearly, salespeople need to develop specific abilities as to which accounts to target, who to focus on within that account and which combination of products and services to promote and sell. In addition, how frequently should they call or support the account and how should they divide their attention between service and developmental selling? For example, one study in the banking industry found that internal management procedures caused more than 90 per cent of relationship breakdowns. ${ }^{4}$ This outlines the importance of planning sales practices with a relationship orientation in mind and the importance of the need for integration and communication flow between the different functions as well as between the buyer and seller in the relationship.

There is some help in the literature on these issues. Burns and Stalker ${ }^{5}$ and Lawrence and Lorsch ${ }^{6}$ developed the contingency approach whereby a mechanistic system is most appropriate for firms operating under stable conditions but, in contrast, an organic system is most appropriate for firms operating in a less stable environment where the need for additional information and interpersonal communication is very important during task execution. This presents a conundrum. At the initial stages of the relationship, where the two sides (buyer and seller) try to know each other, an organic system seems most appropriate. Yet, in view of possible conflicts, the need arises for clear rules and procedures for handling conflicts; the latter is closer to a mechanistic system rather than organic. In the later stages of the relationship process it can be suggested that trust and commitment reduce uncertainty; a fact which can give rise to economies by means of a well-regulated mechanistic system. Yet in view of the high trust and commitment the relationship partners embark on tasks of high complexity; a fact which gives rise to the need for an organic system. Mintzberg claims that 'although we can characterise certain organisations as bureaucratic or organic overall, none is uniformly so across its entire range of activities ${ }^{7}$ - future research is needed to examine this in order to overcome the conundrum.

Yet, in both mechanistic and organic relationship management/development the demands on the sales manager are essentially the same. What are the sales team expected to achieve? How should their time allocation be deployed and 
Sales information systems: Are they being used for more than simple mail shots?

Table 1: Classification by size

\begin{tabular}{llrrr}
\hline & Smallest & Largest & Mean & Median \\
\hline Size of firm & 12 & 70,000 & 3,217 & 500 \\
Number of outside sales force & 0 & 2,000 & 211 & 25 \\
Number of inside sales force & 0 & 12,000 & 260 & 20 \\
Total number in sales and service & 3 & 25,000 & 1,140 & 170 \\
\hline
\end{tabular}

their effectiveness and efficiency increased? To answer these questions the authors conducted this quantitative survey of marketing and sales managers in the financial service area.

\section{METHODOLOGICAL NOTE}

The approach was based on a quantitative survey of a sample of sales and marketing managers in banks, building societies and insurance companies taken from the Marketing Managers Yearbook 2001. ${ }^{8}$ A number of companies were contacted by telephone to enlist their cooperation and 142 companies were selected - based on those who would have a sizeable sales force. Merchant banks and some stockbrokers were deliberately removed from the list. After a repeat mailing, 72 usable responses were received on which results this paper is based.

Respondents were generally the marketing or sales director/manager $(72$ per cent) but no differences were found on the basis of type or position of respondent. The authors consider that the sample is representative of the financial services sector while favouring larger firms with a substantial sales presence.

The questionnaire attempted to measure attitudes towards sales automation systems although several questions are fact finding. In essence, the authors were interested in the use and sophistication of sales information systems and attitudes towards their efficiency and effectiveness. The questionnaire measured attitudes using a seven-point scale with a number of additional questions that were simple counts or measures of a more factual nature.

\section{FINDINGS}

The findings are reported in the following manner. First, the sample's basic

characteristics and use of sales information systems (SIS) are described. An attempt is then made to assess the purpose that these systems have been put to in financial services organisations and the expectation of managers in terms of delivery and performance. Finally, the extent to which they assess the performance of such systems in light of the use to which they have been put is measured.

As Table 1 shows, within the 72 respondents, the size of firm ranged from 12 people to over 70,000 employees with an average size of 3,200 . Outside sales force size ranged up to 2,000 with a median of 25 . Inside sales ranged from 0 to 12,000 and the total employed in sales and service was a minimum of 3 up to 25,000 employees.

\section{Use of SIS}

Almost all claimed to be using some form of automated sales information system. These systems are now widely available and used by financial services companies. In the sample 92 per cent had some form of system and 89 per cent claimed to have an automated SIS. The average time they had been using such systems was seven years. The level of sophistication is, however, highly 
Table 2: Description of SIS

\begin{tabular}{|c|c|c|c|}
\hline & & Mean & $\begin{array}{l}\text { Standard } \\
\text { deviation }\end{array}$ \\
\hline 2.1 & Our system is almost totally manual & 5.2 & 1.7 \\
\hline 2.2 & $\begin{array}{l}\text { Sales personnel can easily obtain all data they need from our } \\
\text { system }\end{array}$ & 4.2 & 1.8 \\
\hline 2.3 & $\begin{array}{l}\text { Our system has many interfaces with external commercial } \\
\text { databases }\end{array}$ & 2.1 & 1.4 \\
\hline 2.4 & Computerisation of systems create more problems than solutions & 5.8 & 1.2 \\
\hline 2.5 & $\begin{array}{l}\text { Our system holds customer information files which are directly } \\
\text { accessible by sales personnel }\end{array}$ & 4.9 & 2.2 \\
\hline 2.6 & Customer information files cannot be justified on cost grounds & 6.0 & 1.4 \\
\hline 2.7 & $\begin{array}{l}\text { Our system allows product cross holdings by customer to be easily } \\
\text { identified }\end{array}$ & 4.4 & 2.1 \\
\hline 2.8 & $\begin{array}{l}\text { Our system records and stores responses to all sales campaigns in } \\
\text { the customer information file }\end{array}$ & 3.5 & 2.2 \\
\hline 2.9 & $\begin{array}{l}\text { Sales personnel always use customer information to direct mailings } \\
\text { and/or other promotion activities }\end{array}$ & 4.2 & 1.9 \\
\hline 2.10 & $\begin{array}{l}\text { Our system has statistical capabilities to analyse all sales and/or } \\
\text { customer data }\end{array}$ & 4.5 & 1.9 \\
\hline 2.11 & Our system is not very user friendly for sales purposes & 4.0 & 1.7 \\
\hline 2.12 & $\begin{array}{l}\text { The sales department has access to software for customer } \\
\text { development purposes on our system }\end{array}$ & 3.6 & 1.9 \\
\hline 2.13 & Our SIS is extremely sophisticated & 3.3 & 2.0 \\
\hline 2.14 & Our SIS is built around up-to-date technology & 3.5 & 2.0 \\
\hline 2.15 & $\begin{array}{l}\text { Our IT people can design and install all software suitable for sales } \\
\text { purposes }\end{array}$ & 3.5 & 2.0 \\
\hline
\end{tabular}

variable. Using a seven-point scale, ranging from one 'low level' to seven 'high level', most perceived themselves as a four (mean 4.03, standard deviation 1.65) suggesting a slightly above average level of perceived sophistication. So, what are the characteristics of adopted SIS systems?

Table 2 documents responses to questions where one indicates agreement with the statement and seven disagreement.

Inspection of Table 2 reveals that evidence of computerised systems creating more problems than they solve, or a desire to return to the 'good old days' of manual systems, was distinctly absent. Although it was by no means unanimous, relatively few had major problems accessing data they felt they required (question 2.2). Further, costs or IT resources were not seen as limiting factors (questions 2.6 and 2.12). This may indicate that, in terms of IT systems and information, demands are being driven less by marketing and sales personnel. For example, the ability to identify cross-selling opportunities is still not well developed for many respondents (question 2.7). In general, Table 2 reveals that there are perceived problems in using data for anything other than mailings to clients. Developments such as measuring responses to sales and promotional campaigns seem relatively low key (questions 2.10 and 2.9) yet most respondents, as discussed, perceive themselves as slightly above average in the sophistication of their SIS.

\section{Objectives for SIS}

Respondents are asked how important certain objectives were for their SIS. Table 3 shows means and standard deviations for these objectives on a scale from one, not at all important to seven, crucially important.

As Table 3 reveals, the purpose of these systems appears quite general, with 
Table 3: Objectives for SIS?

\begin{tabular}{llll}
\hline & Importance of following & Mean & $\begin{array}{c}\text { Standard } \\
\text { deviation }\end{array}$ \\
\hline 3.1 & Increased customer acquisition & 5.7 & 1.2 \\
3.2 & Increased customer retention & 6.1 & 0.9 \\
3.3 & Enhanced customer relationships & 6.1 & 1.2 \\
3.4 & Integration to contact management & 5.5 & 1.4 \\
\hline
\end{tabular}

Table 4: Items measured in using SIS

\begin{tabular}{lc}
\hline If you measure results, please tick if you measure the following: & $\begin{array}{c}\text { Numbers } \\
\%\end{array}$ \\
\hline Number of potential customers reached & 53 \\
Opportunities identified & 69 \\
Number of customer gained & 74 \\
Sales by segments & 69 \\
Number of sales generated & 81 \\
Revenue per customer & 66 \\
Share of customer business & 38 \\
Cost per customer business & 43 \\
Cost per sale generated & 47 \\
Contribution to profits & 79 \\
Level of customer satisfaction & 62 \\
Individual customer value & 36 \\
Effectiveness of different marketing mix elements & 38 \\
Effectiveness of different contact strategies & 38 \\
Relationship enhancement & 39 \\
Overall marketing operations & 42 \\
Other & 8 \\
\hline
\end{tabular}

most respondents claiming to use them for customer acquisition, customer retention, improved customer relationships and contact management integration. Further analysis clarifies this result however. As seen above, generally, sales and marketing people perceive that their systems operate at a mid-level of sophistication but further investigation indicates that they have, in fact, a 'mailing list mentality'. Table 4 shows this.

For example, although most measure the number of sales generated, the number of customers gained, revenue increases and opportunities identified, relatively few measure more problematic areas such as individual customer value, share of customer business, effectiveness of different marketing mix elements, or efficiency of different customer conduct strategies. About 40 per cent do not measure customer satisfaction at all and only about 30 per cent attempt to predict customer potential. Costs per customer and costs per sale are also not measured by 50 per cent of the sample. Even more surprising is the low level, less than 40 per cent of the sample, who measure the degree of a relationship enhancement. Clearly, the objectives set for the SIS cannot be met by the results that are, in fact, measured by the sample of financial services firms. Table 5 further clarifies this inference.

\section{Type of information being held}

As Table 5 reveals, sales and marketing managers generally feel they have adequate information and at least 50 per cent of the sample do not see the need for any more. Yet, as Table 5 reveals, both the quantity and quality of 
Table 5: Information held

\begin{tabular}{lcc}
\hline $\begin{array}{l}\text { What information is presently } \\
\text { held or would you like to hold } \\
\text { in the customer information file }\end{array}$ & \% Presently held & \% Would like to hold \\
\hline Name and address & 100 & 8 \\
Post code & 100 & 8 \\
Telephone number & 97 & 9 \\
Fax & 69 & 13 \\
E-mail & 73 & 27 \\
Names of all contacts & 66 & 25 \\
Customer order history & 56 & 22 \\
Purchasing profile & 35 & 38 \\
Own products held & 61 & 19 \\
Competitors' products held & 14 & 51 \\
Previous contact response details & 43 & 35 \\
Credit rating & 29 & 19 \\
\hline
\end{tabular}

information held is at a low level of complexity. Indeed, it is asserted that the information held is much less than salespeople traditionally held on one side of an index card. As expected, almost all hold name, address and telephone number but far fewer have fax, e-mail or the names of different contacts with customers. Table 5 shows the extent to which different types of data are held.

In terms of data that would really make a difference in the strategic use of SIS — such as purchasing profiles, competitor products or services held and previous contact records - the data held by the financial services organisations, are relatively sparse. In the authors' view, firms which do not have this basic knowledge will not truly understand their customers better and so will not prosper in an age of customer relationship management.

\section{Uses of SIS}

Respondents were next asked the degree to which they used SIS for aspects of sales planning on a scale from one, 'not at all' to seven, 'comprehensively. Table 6 sets out the findings.

As Table 6 reveals, SIS are being used extensively in sales planning for a variety of purposes but, as expected, the major use is to develop mailing lists. Table 7 addresses the degree to which respondents utilised SIS for operational uses using the same response scale as in Table 6.

As Table 7 reveals, SIS is much less utilised for operational purposes. The strongest use is made of SIS for contact

Table 6: Sales planning uses for SIS

\begin{tabular}{lll}
\hline Utilisation of: & Mean & $\begin{array}{l}\text { Standard } \\
\text { deviation }\end{array}$ \\
\hline Mailing list & 5.3 & 1.6 \\
Customer profiling & 4.6 & 2.0 \\
Prospect bank & 4.3 & 2.0 \\
Lead generation & 4.6 & 1.8 \\
Segmentation & 4.6 & 1.8 \\
Campaign effectiveness & 4.3 & 1.8 \\
& & $\mathrm{~N}=72$ \\
\hline
\end{tabular}

Table 7: Operational uses for SIS

\begin{tabular}{lll}
\hline Utilisation of: & Mean & $\begin{array}{l}\text { Standard } \\
\text { deviation }\end{array}$ \\
\hline Ordering systems & 2.5 & 2.0 \\
Billing system & 3.2 & 2.3 \\
Customer care/service & 3.8 & 2.0 \\
$\quad$ system & 4.9 & 1.5 \\
Contact management & 4.2 & 2.0 \\
Sales cycle tracking & 5.4 & 1.5 \\
Sales reports & 4.1 & 1.9 \\
Corporate data warehouse & & $\mathrm{N}=72$ \\
\hline
\end{tabular}


management and sales cycle tracking but very little use is made of SIS for ordering or billing. Remembering customer care is not a major use of the SIS in operational terms - scoring less than half-way up the seven-point scale from not at all to comprehensively.

\section{DISCUSSION AND CONCLUSIONS}

Overall, there has been a

comprehensive adoption of SIS in financial services firms. On average their systems were adopted seven years ago. Advertisements for SIS promise the strategic management of sales through use of these systems in order to enhance customer relationship management. For example, quotations showing the sophistication of the systems include 'getting to know your customers better than you ever dreamed possible, what they liked to be called and how they want you to contact them'. ${ }^{10}$ Another suggests a system that enables multidivisional businesses to capture information from every corner of their extended enterprise. ${ }^{11}$ Yet another claims that success is guaranteed by using a consistent way of working for any number of salespeople, channels to market or country operations. ${ }^{12}$ Users of these systems in financial services have adopted these objectives (as shown in Table 3), but the practical reality, shown in the extent and degree of measurement of sales results and the actual information held on these sophisticated systems, cannot underpin the achievement of these high-level strategic objections. The SIS systems are currently being used as little more than enhanced mailing lists, and, as such, have little advantage over earlier, manual 'index card' sales information systems. Why should this be so? Interviews conducted with sales professionals give a clue. One respondent said, 'as the company grew through high net-worth individuals selling was done through building relationships but customer data was not stored for easy access to the entire organisation'. The result is that no formal database is shared. Further, developments are led by information technology not by marketing or sales. Another respondent suggested that there was a lot of hype about these systems and expectations were too high. As he put it businesses that need a low rate of data transfer (such as low cost flights) will prosper with these systems but our business is a much more complex customer experience. At the moment technology is being pushed at the customer and not being woven or adapted round the customer'.

Choice of supplier and/or consultant appears to be crucial. As it was put by one of the respondents, 'if he could turn back time, he would not choose the consultant they did'. This is confirmed by a more successful implementation example of a large turnover bank. In their case, they added 60 per cent to system costs for feasibility studies, the chief executive was passionate about the new system and the organisation used one external consultant for the entire process from analysis to the integration, testing and training of all personnel. Only if these systems are used in a strategic way will results live up to expectations.

\section{References}

1 Glackin, M. and Burke, L. K. (2001) 'Royal Bank in 6,000 jobs boost', Scotsman, 28th September.

2 Berkowitz, J. (2000) 'Customer relationship management: The defining business initiative of the new millennium', White Paper, Showcase Corporation.

3 Payne, K. (2000) 'Improving sales force productivity', in Reeves, J. (ed.) 'Customer relationship management', Caspian Publishing Ltd., CBI Business Guide London, pp. 58-62. 
4 Perrien, J. and Ricard, L. (1995) 'The meaning of a marketing relationship: A pilot study', Industrial Marketing Management, Vol. 24, pp. 37-43.

5 Burns, T. and Stalker, G. M. (1961) 'The management of innovations', Tavistock Publications, London.

6 Lawrence, P. R. and Lorsch, J. W. (1967) 'Differentiation and integration in complex organisations', Administrative Science Quarterly, Vol. 12, No. 1, pp. 1-47.

7 Mintzberg, H. (1983) 'Structures in fives: Designing effective organisations', Prentice Hall, Englewood Cliffs, N.J.
8 AP Information Services (2000) 'The Marketing Manager's Yearbook', AP Information Service, London.

9 The percentage in 'presently held' and 'would like to hold' adds to more than 100 per cent in some cases. This is interpreted as indicating that a 'presently held' response does not mean that the holding is comprehensive.

10 Advertisement for 'Edify', Winning Business, November/December, 2001, p. 11.

11 Advertisement for 'Applix', Winning Business, November/December, 2001, p. 15.

12 Advertisement for 'Consensus', Marketing Business, November, 1998, p. 34 